\title{
LAS «GALERÍAS" DE ANTONIO MACHADO: ORIGEN Y EVOLUCIÓN DE UNA METÁFORA CENTRAL DE SU POESÍA
}

\author{
HANS MATTAUCH \\ Universidad Técnica de Braunschweig \\ El poeta crea a la manera del hombre: transfor- \\ mando una cosa en otra $o$, si queréis, dando una \\ forma a una materia.
}

A. MACHADO,

Dos preguntas de Tolstoi (1920)

En vista de la advertencia muy acertada de Ricardo Gullón de que «el estudio de los versos de Antonio Machado debiera comenzar por [....] el elemento propiamente básico [...], es decir, por el análisis del lenguaje» ${ }^{2}$, es algo paradójico que la crítica machadiana, al parecer, no se haya interrogada nunca sobre el origen de la metáfora de «galerías» que, al lado de otras palabras-claves como «sueño» o «recuerdo», tiene suma importancia en la temprana poesía del poeta. La razón de esta despreocupación es quizá que «galerías» parece resumir de manera tan natural la quintaesencia de una faceta de la inspiración del poeta que se puede creer en una especie de creatio ex nihilo de la metáfora de su parte. Sin embargo, él mismo nos advierte - véase el epígrafe- que en el proceso poético no importa la «invención» (no fue Machado el primero quien utilizó «sueño» o «recuerdo»), sino el arte de dar «forma a una materia». Dado esto, es menester examinar si en el caso de «galerías» se trata efectivamente de una creación suya o si la tradición literaria europea le ofreció referencias de las que puede haber tomado la metáfora, para después cargarla de la plenitud de significación que tiene en su obra.

Cabe advertir, sin embargo, que no intentamos añadir un análisis más

\footnotetext{
${ }^{1}$ Los textos del poeta se citan según Poesía y Prosa, edición crítica de Oreste Macrì 4 vols., Madrid: Espasa Calpe/Fundación Antonio Machado 1989 [sigla: PyP, seguida por la indicación del tomo y la(s) página(s)]. La citación-epígrafe en PyP II, 1614.

${ }^{2}$ R. Gullón, Las secretas galerías de Antonio Machado, Madrid: Taurus 1958, p. 15.
}

Rlit, LXV, 129 (2003), 225-235 
a los numerosos y valiosos trabajos consagrados a la totalidad de las poesías que constituyen la (nueva) sección de «Galerías» en las Soledades de 1907. Se trata de un propósito más limitado: examinaremos sólo las publicadas originalmente bajo este título y aquellas donde la palabra aparece en el texto, refiriéndonos a algunas otras sólo por incidencia, cuando sean relevantes para nuestra investigación.

La tradición poética española parece desconocer el uso metafórico de «galería(s)» en el sentido machadiano. Al contrario, encontramos la metáfora de la mina en el romanticismo alemán (Novalis, E. T. A. Hoffmann) y francés (G. de Nerval) ${ }^{3}$; allí, sin embargo, se trata siempre de un totum - es decir de la mina simbolizando globalmente el lugar de hallazgo sea de riquezas espirituales, séa de la inmortalidad-, y nunca de la pars - del camino subterráneo horizontal que conduce al yo poético machadiano en los rincones más escondidos de su ser espiritual y emocional-, diferencia conceptual marcada que excluye toda analogía. Por otra parte, el tratamiento de la mina en la narrativa realista y naturalista, en Zola y Pérez Galdós entre otros, acentuando problemas sociales y/o psicológicos, está todavía más lejos de nuestro propósito.

Sin embargo, existe un texto que muestra un parecido sorprendente en el uso metáforico de «galerías», tal y como lo encontramos en Machado. Se halla en la famosa novela titulada $\grave{A}$ rebours (1884) de Joris-Karl Huysmans. Allí, en el cap. XII (que es el segundo de los consagrados a las lecturas sofisticadas de Des Esseintes), el campo semántico de la mina está explotado metaforicamente para un juicio estético de alcance general, desembocando en un elogio vibrante de Baudelaire, tan superior, al parecer del personaje, a los demás poetas en la exploración de los abismos del alma humana:

Son admiration pour cet écrivain était sans borne. Selon lui, en littérature, on s'était jusqu'alors borné à explorer les superficies de l'âme ou à pénétrer dans ses souterrains accessibles et éclairés, relevant, ça et là, les gisements des péchés capitaux, étudiant leurs filons, leur croissance [...]

[....]

Baudelaire était allé plus loin; il était descendu jusqu'au fond de l'inépuisable mine, s'était engagé à travers des galeries abandonnées ou inconnues, avait abouti à ces districts de l'âme où se ramifient les végétations monstrueuses de la pensée ${ }^{4}$.

\footnotetext{
${ }^{3}$ Kurt RINGgER/Christoph WEIAND, «Aspects littéraires de la mine», Revue de littérature comparée 58 (1984), pp. 417-41. Los autores no se refieren a la literatura española.

${ }^{4}$ À rebours, Paris 1978, p. 177 (Coll. Garnier-Flammarion); las cursivas son mías. Ringger/Weiand (nota 3 ) no mencionan a Huysmans.
} 
¿Sería este pasaje la «fuente» del concepto machadiano de «galerías»? En lo que sigue nos proponemos demostrar la validez de esta conjetura por medio de un nuevo examen de todos los datos disponibles (las poesías, cartas, críticas etc. del poeta) y contribuir así a esclarecer uno de los problemas más arduos de la investigación sobre Machado, es decir, el papel de Las flores del mal en su poesía. Esta indagación dara además lugar a reexaminar la evolución de su estética en los años 1903 y 1904, lo que incluye la discusión de su posición frente a las ideas de Unamuno en los comienzos de la relación entre los dos.

Lo que a primera vista parece ser obstáculo a nuestra hipótesis es el hecho de que el poeta nunca ha mencionado a Huysmans en su obra y una sola vez a Baudelaire, en tiempos muy posteriores $^{5}$. A pesar de esto, la crítica machadiana se muestra convencida de la familiaridad de Machado con la obra del poeta francés desde el primer decenio del siglo XX, divergiendo sólo sobre la importancia de la «influencia» que ella ejerció y sobre puntos de cronología ${ }^{6}$.

En lo que a la novela singular de Huysmans se refiere, parece difícil afirmar por principio que Machado ignoró este libro, llamado a menudo la biblia de los estetas y «decadentes» (no sólo franceses) del fin de siglo decimonónico: hay que recordar sus dos estancias en París y sus relaciones con literatos imbuidos de literatura francesa (por ej. Enrique Gómez Carrillo). Lo que aboga de manera precisa en favor de un conocimiento del pasaje huysmaniano son los poemas tempranos del poeta, en particular las fechas de su publicación (e, implícitamente, de su creación). En efecto: según dice él mismo, las composiciones contenidas en las primeras Soledades, salidas en enero de 1903 , fueron escritas «entre 1899 y $1902 »^{7}$; por consiguiente, las composiciones que publicó en 1903 y 1904 son seguramente posteriores a esta edición. Su primera contribución a Helios $\left(\mathrm{n}^{\circ}{ }^{\mathrm{j}}\right.$; julio de 1903) consiste en cuatro piezas, tituladas sencillamente «Poesías», mientras en la segunda (no. 8; noviembre), abarcando siete poemas, surge — casi de la nada ${ }^{8}$ - el título colectivo de «Galerías» para cuatro de ellos.

\footnotetext{
${ }^{5}$ Cf. Luis LóPEZ JimÉNEZ, «Don Antonio Machado, lector y crítico de la literatura francesa», Antonio Machado, hoy (Actas del Congreso internacional, Sevilla 1989), 4 vols., Sevilla: Alfar 1990, t. IV, p. 76.

6 Véanse por ej. Geoffrey W. RiBbans, Niebla y soledad: Aspectos de Unamuno y Machado, Madrid: Gredos 1971, pp. 274, 276, 278, y «Antonio Machado y Mallarmé», Revista hispánica moderna 39 (1976/77), pp. 183-97 (en part. p. 185); Bernard SESÉ, «Baudelaire et Antonio Machado», Les langues néolatines 203 (1973), pp. 34 -47; Pere RovirA, «Las soledades del splin», Antonio Machado, hoy (nota 5), t. I, pp. 497-505.

7 PyP III, 1592 (Prólogo a Soledades, 1917).

${ }^{8}$ Esta repentina aparición de la metáfora la subrayó ya Mátyás Horányi en su valioso libro Las dos Soledades de Antonio Machado, Budapest 1975, p. 129. Debe señalar-
} 
$\mathrm{Y}$ fueron seguidos de otros más, de modo que en las contribuciones del poeta a Helios y Alma española ${ }^{9}$, entre noviembre de 1903 y mayo de 1904, las «Galerías» constituyen no sólo el grupo más numeroso (ocho) ${ }^{10}$, sino también la gran mayoría de todas las poesías al respecto (doce). Estos

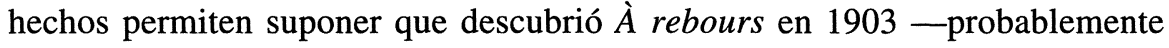
en los comienzos del año- y que el hallazgo de la metáfora huysmaniana le causó un verdadero flechazo (poético), flechazo que parece haberle incitado a una (nueva) lectura de Las flores del mal y además se reveló durable, ya que el poeta, después de elegir la metáfora como título de la larga sección nueva de las Soledades revisadas, la reutilizó todavía muchos años más tarde ${ }^{11}$.

Antes de desarrollar el problema de la relación Machado - Baudelaire, conviene analizar el uso que el poeta español hizo de la metáfora entre los últimos meses de 1903 y la publicación de las segundas Soledades. La perspectiva cronológica revela dos fases distintas. En la inicial (1903-04) se sirvió de ella sobre todo como título llamativo (¿quizás aún críptico?) ${ }^{12}$ y la incluyó bastante raramente en su discurso poético: no ocurre en los textos de la mitad de las ocho primeras «Galerías», dos veces está descartada, casi a propósito, en favor de un «sinónimo» (cripta, LXIII; corredor, P.s. XX), una vez se menciona, ya con connotaciones simbólicas, una larga, escueta galería (LXIV) y sólo una vez, en $Y$ nada importa ya (LXX), la palabra, ampliada por complementos significativos, despliega toda su fuerza metafórica:

Tu sabes las secretas galerías del alma, los caminos de los sueños y la tarde tranquila donde van a morir....

se, sin embargo, el empleo aislado de «galería» (al singular) en Siempre que sala el alma (P.s. VIII), publicado en Electra el 30 de marzo de 1901.

${ }^{9}$ Las indicaciones relativas a las dos revistas provienen de María Pilar Celma VALERO, Literatura y periodismo en las revistas del Fin de Siglo. Estudio e Indices (1888-1907), Madrid: Júcar 1991.

${ }^{10}$ Los títulos colectivos de "Tristezas» e «Impresiones de otoño» recogen dos poesías cada uno y «Soledades» una sola; algunas otras piezas llevan títulos individuales.

${ }^{11}$ Una secuencia de siete breves poesías en Nuevas canciones (1924) se titula de nuevo «Galerías» (PyP II, 612-15; no. CLVI).

${ }_{12}$ El trasfondo de la metáfora pudo ser ententido a lo más por algunos modernistas «iniciados», para los demás lectores ella quedó sin duda algo misteriosa, a pesar del sentido preciso de «corredor subterráneo» que se destaca de las dos primeras poesías publicadas bajo el lema (LXIII y LXIV). 
A partir de 1905, al contrario, la metáfora no reaparece como título colectivo o individual, sino está siempre incorporada en el texto poético propiamente dicho: las galerías del alma resurgen en la primera parte de Renacimiento (LXXXVII; 1905) y en El poeta (XVIII; 1907), mientras la variante importantísima las galerías del recuerdo se encuentra por primera vez en Coplas mundanas (XCV; 1907) y, alargada todavía - esas galerías, / sin fondo, del recuerdo-, en los versos titulados más tarde Introducción (LXI), la creación más reciente de todas y destinada a formar el pórtico de la nueva sección de las segundas Soledades.

Se trata, pues, de una evolución claramente marcada, en la que «galerías» se transforma de una voz casi unicamente lemática en metáfora que respresenta la búsqueda del yo lírico en los abismos de su alma y se enriquece finalmente de la dimensión temporal, transcendiendo así el tiempo presente por la inclusión del pasado recordado.

Si el impacto del pasaje huysmaniano indujo a Machado a adoptar «galerías» como metáfora significante, es sin duda porque le impresionó también la descripción de los logros poéticos de Baudelaire, presentados allí como fruto de una exploración de los rincones «abandonados o desconocidos» del alma, que debió parecerle emparentada con la suya propia. Esto no excluye un conocimiento anterior, probablemente no profundizado, de las (o de algunas) poesías de Las flores del mal: parece difícil, en efecto, negar que la «clepsidra» de Daba el reloj las doce (XXI; 1902) no provenga de la «clepsydre» de L'Horloge (LXXXV), por ser rarísima la palabra en textos literarios de ambas lenguas ${ }^{13}$. Sin embargo, no salta menos a la vista la manera completamente diferente de los dos poetas en el tratamiento del tema (el reloj como memento mori): Baudelaire describe la congoja de un reprobado consciente de su condena moral irremediable, Machado el susto frente a la idea de la muerte, calmado por la de un despertar idílico en «una mañana pura» - movimiento realizado con imágenes que evocan otras poesías de Las flores ${ }^{14}$. Este poema, pues, parece indicar que Machado dio su propia «forma a una materia» ajena tanto libre como originalmente y nos advierte que debemos prepararnos a encontrar en él

\footnotetext{
${ }^{13}$ Hizo hincapié en este término G. W. RiBbans en Niebla y soledad (nota 6), p. 276. Hipótesis tanto más probable que la voz no pertenece al léxico de Verlaine. El mejor gran diccionario del francés, Le Robert (9 vols., Paris: Le Robert 1985), documenta no más que tres ocurrencias -en Fontenelle, Víctor Hugo y Michel Tournier-, los diccionarios del español no citan a ningún autor.

${ }^{14} \mathrm{La}$ idea de que el momento de la muerte no se siente está expresada en Le rêve d'un curieux (CXXV), la de un despertar idílico en la otra vida en La mort des amants (CXXI).
} 
no sólo «resonancias» (en el sentido de «analogías verbales») de Baudelaire, sino también transformaciones considerables de los «préstamos» tomados de éste. Es en esta perspectiva que nos proponemos demostrar una lectura atenta de Las flores del mal por parte de Machado en 1903, mediante el análisis de la presencia de significantes elementos baudelairianos en poesías escritas en los meses siguientes, es decir las publicadas en Helios y Alma española y tituladas «Galerías».

Llama inmediatamente la atención el hecho de que el primer grupo de éstas era encabezado por $Y$ era el demonio (LXIII) y Desde el umbral de un sueño (LXIV), verdadero díptico en la concepción del poeta (quien nunca las separó) ${ }^{15}$ y que muestra estados de ánimo extremos: el yo, por un lado sucumbiendo a la fuerza de impulsos satánicos, por otro lado pasando por una «larga, escueta galería» (¿la del hastío?) hacia la vista del «alma», guiado por una «mano amiga» tierna y protectora. A nuestro parecer, pues, este díptico abarca en abreviatura la dicotomía baudelairiana de «Spleen et Idéal»; además, varios detalles corresponden con otras rimas de Las flores, así, la presencia y el poder del demonio («Sans cesse, à mes côtés, s'agite le démon»; La destruction, CIX), la representación de los impulsos viciosos por animales feroces (cf. «les monstres glapissants, hurlants, grognants, rampants»; Au lecteur) o el consuelo impartido por la mujer amiga (o el principio femenino) ${ }^{16}$. Al díptico sigue $Y$ nada importa ya (LXX), diálogo del yo lírico consigo mismo, que muestra a su vez otro tipo de dualismo baudelairiano, a saber la indiferencia del poeta respecto a los valores morales de los objetos de su inspiración en la búsqueda de la creación de lo bello. Parece típico de la tonalidad generalmente más moderada —o menos «extática»- de Machado, que la violenta oposición entre «ciel» y «abîme» en Hymne à la beauté (XXI) sea sustituida por aquella entre «el vino de oro» y «el agrio zumo», presente sólo en los versos iniciales, mientras en el resto domina la convicción del poeta de poseer la verdad interior «de los sueños» que le «llevarán un día» (¿después de la muerte?) a «un jardín de eterna primavera». Totalmente desprovista de tal armonización - no baudelairiana - es la última poesía de este primer grupo, $Y$ en una triste noche me aguijaba (P.s. XVII). Allí, el yo lírico está sobrecogido por el espanto al enterarse del vacío espiritual-afectivo del mundo, el alma del cual se ha retirado al más allá: el sentimiento de que «la tierra ha muerto» y no es más que un amontonamiento caótico de objetos sin significación, lo traducen con particular intensidad en Baudelaire varios de los poemas titulados «Spleen» (LXXV, LXXVI).

\footnotetext{
${ }_{15}$ Por eso discrepamos con la opinión de R. Gullón (nota 1) quien considera estos dos poemas, aunque «ligados», como «independientes» (p. 42). El único crítico quien se dio cuenta de la estrecha conexión entre ellos («nos ofrecen los extremos del sueño nocturno») es Julián Palley («Las secretas galerías de Antonio Machado», Cuadernos americanos 34, 3 (1975), p. 221).

${ }^{16} \mathrm{Cf}$. La géante (XIX), Chant d'automne (LVI), Le vin des amants (CVIII).
} 
La continuación de estas primeras «Galerías» la constituyen las dos, extrañamente contrastantes, que salieron a luz en el no. 11 de Helios (febrero de 1904). Por una parte, Arte poética (P.s. XVIII) continúa la vena de desesperación, dominante en $Y$ en una triste noche, por el cambio repentino del estado de ánimo del que habla (alma «en fiesta» - alma «[llena de] andrajos, rencor»), movimiento mental que desemboca en la expresión sarcástico del deseo de una muerte instantánea (también tema baudelairiano) ${ }^{17}$, por otra, Los sueños (LXXXII) forma una especie de idilio, ajeno a toda temática baudelairiana, con el cuadro de dos hadas «hilando de los sueños / los sútiles copos» para un niño adormecido en su cuna.

Hay que constatar, pues, radicales cambios de tonalidad en ambos grupos, y esta fluctuación entre dos maneras líricas en poesías reunidas bajo el mismo lema, parece indicativa de tanteos y dudas del poeta, lo que corroboran ciertas de sus enunciaciones durante los primeros meses de $1904^{18}$.

La siguiente «Galería», Yo he visto mi alma en sueños (P.s. XX), publicada un mes más tarde en Alma española ${ }^{19}$, presenta en cinco estrofas otras tantas imágenes (o «definiciones») del alma, tres de ellas pintadas en colores sombríos («astro loco» - «corredor tenebroso» - «desierto llano») y encuadernando dos estrofas marcadas de huellas más agradables («río plateado» - «risueña luz del campo»), de modo que los versos terminan sobre una nota de abatimiento, siendo el alma finalmente no más que «un árbol seco y roto». Por eso, estos versos nos parecen una aplicación sistemática (casi geométrica) de la autodenigración del yo que habla en Spleen (LXXVI) de Baudelaire («Je suis un cimetière...» - «Je suis un vieux boudoir...») y vemos en ellos una prueba más del vivo interés de Machado en este grupo de poemas de Las flores del mal.

La última de estas primeras «Galerías», publicada en Helios (n..$^{\circ}$ 14; mayo de 1904), es Desgarrada la nube (LXII) en la que se presenta de nuevo un contraste violento, esta vez entre una visión onírica de cielo y tierra la cual, en el despertar, se desvanece «como una pompa de jabón al viento», dejando el corazón del yo «atónito y disperso». Este quebranto doloroso de «los mágicos cristales de[1] sueño» lo había evocado Baudelaire en Rêve parisien (CII), poema que a pesar de su estructura e imágenes muy diferentes finaliza con la misma experiencia.

Con el fin de Helios coincide él de la primera serie de «Galerías», la más compacta y numerosa. No seguiremos analizando las cuatro poesías posteriores al respecto porque aparecieron sólo con intervalos considerables (en 1905 y 1907), hecho que sería ya en sí una indicación suficiente

\footnotetext{
${ }^{17}$ Cf. Le mort joyeux (LXXII), Le goût du néant (LXXX).

18 Sobre este punto véase la siguiente sección del presente estudio.

19 T. II, no. 19 (20 de marzo de 1904).
} 
de un cambio en la orientación estética del poeta, si no fuera patente la ausencia en ellas de temas y huellas baudelairianos ${ }^{20}$.

Lo que se desprende de la evidencia «interna» de los poemas, sobre todo de las «Galerías» de 1903-04, está confirmado por los testimonios «externos», es decir los comentarios del poeta — desafortunadamente escasos e incompletos - sobre su poesía y estética durante estos meses cruciales. Se encuentran en varias cartas a Juan Ramón Jiménez escritas en los primeros meses de $1904^{21}$ (de ellas hablaremos en seguida), pero principalmente en escritos pertenecientes a la primera fase de su relación con Unamuno, que ha sido descrita a veces como una de «total aceptación de discipulado por parte del joven poeta» ${ }^{22}$, por ej. sobre la base de su declaración en una carta de agosto de 1903 al «maestro» diciendo que «empiezo a creer [...] que el artista debe amar la vida y odiar el arte. Lo contrario de lo que he pensado hasta aquí» ${ }^{23}$. Pero ies esto un indicio suficiente de una «total aceptación» de los puntos de vista de Unamuno sobre estética? Recordemos que la relación entre los dos la inició el poeta haciendo mandar un ejemplar de las primeras Soledades a Unamuno, envío seguido (¿en julio?) por una carta (perdida) del contenido de la cual nos informan sólo algunas citas que incorporó Unamuno en su carta abierta a Machado, titulada «Vida y Arte» y publicada en el n. ${ }^{\circ} 5$ de Helios (agosto de 1903) ${ }^{24}$. En ella Unamuno preconizó una poesía castiza e independiente de modelos franceses aptos para nada más que para inducir a los errores del arte por el arte como «los sonetos de Heredia» y «las atrocidades de Baudelaire». Si se comprende sin dificultad su crítica de las cinceladuras del primero en los Trophées, su invectiva contra el segundo no deja de extrañar, dada la difusión todavía escasa de la obra de Baudelaire entre los

\footnotetext{
${ }^{20}$ Aunque El poeta (XVIII) trata el tema del poeta desdichado (sino maldito), no ausente de Las flores del mal (Bénédiction, I; L'albatros, II), es indudablemente de carácter rubendariano. Cf. el comentario de O. Macrì en $P y P$ II, 851-52, y su estudio «La presencia de Rubén Darío en Antonio Machado», Studi e informazione I (1972), pp. $1-50$.

${ }^{21}$ Estas cartas están fechadas en $P y P$ III de «1903-1904», pero como en una de ellas Machado dice que quiere discutir con el amigo su reseña de Arias tristes (salida en marzo) antes de publicarla (III, 1462-63) y en otra le felicita por el "gran éxito de crítica» del libro (III, 1464-65), la fecha que proponemos parece bien establecida.

${ }^{22}$ Aurora DE Albornoz, La presencia de Miguel de Unamuno en Antonio Machado, Madrid: Gredos 1968 (BRH II, 106), p. 26. G. W. RIBBANS, «Unamuno and Antonio Machado», Bulletin of Hispanic Studies 34 (1957), pp. 10-28, presenta indicios (p. 14) que invitan a una actitud más reservada.

${ }^{23}$ Frase citada, entre otros, por Albornoz y Ribbans (nota 22), p. 26 y 11, respectivamente.

${ }^{24}$ Carta reproducida por Ribbans (nota 22), pp. 10-13.
} 
modernistas ${ }^{25}$. $i Y$ porque dirigir dicha carta abierta ( $i$ !) expresamente a Machado? ¿Habría éste mencionado al poeta francés en su carta de julio? ¿O - suposición más osada- habría mandado entretanto su «díptico» ya compuesto a Unamuno que en él husmeó el olor baudelairiano? Sea como fuera de esta hipótesis: consta que a pesar de la admonestación unamuniana Machado publicó el díptico tres meses más tarde, hecho que, cuadrando mal con la presunta sumisión a las opiniones del «maestro», demuestra más bien la resolución del poeta de conservar su originalidad y constituye al mismo tiempo una prueba indirecta de su entusiasmo por el poeta de Las flores del mal en este momento.

Otra prueba de esto la proporciona su reseña de Arias tristes (marzo de 1904) que, a pesar de que se distancia de la actitud solipsista, del «soñar fantástica y egoísticamente», de Juan Ramón Jiménez y reitera su gratitud a Unamuno por haberle estimulado a abrirse al mundo, a «soñar despierto», contiene una manifiesta reservatio mentalis en cuanto a las fuentes de su propia inspiración, casi finalizando el poeta con un breve párrafo, curiosamente desatendido por la crítica machadiana:

Que el poeta sea o no castizo, cosa es que importa poco, a mi juicio; que sus ascendientes literarios estén en la poesia española o en la francesa, es cuestión baladí. Si el casticismo no es ingénito ¿a qué adoptarlo? (PyP III, 1471-72)

La firmeza de esta declaración que reduce a «cuestión baladí» el casticismo, erigido casi en dogma por Unamuno, no permite dudar de que estas líneas no constituyen una mera apología del poeta amigo, sino más bien una verdadera autodefensa por parte de Machado $^{26}$ quien en aquel momento mismo no sólo repitió su descuido por el casticismo en una carta a Juan Ramón («tiempo tendremos [....de ser] pulidos, retóricos y hasta castizos»; PyP III, 1464), sino siguió escribiendo poemas con tonalidad baudelairiana que obviamente no consideraba como productos de una somnolencia hiperestética.

Es innegable, por otra parte, que Machado fue en rápida evolución durante la época de Helios. La aparición de las «Galerías» en noviembre de 1903 marca una primera etapa dominada por tonalidades extremas, reflejo de «excavaciones» en estratos psicológicos escondidos y extraños. Lo que demuestra que el poeta creía haber encontrado un terreno inexplorado

\footnotetext{
${ }^{25}$ La afirmación de Ramón de Maeztu de que a principios del siglo «frente al cocido casero, una página de D'Annunzio o un soneto de Baudelaire parecía transportarnos a un mundo superior y más selecto» debe ponerse en tela de juicio, por ser posterior de tres decenios (cit. en J. M. AguirRe, Antonio Machado poeta simbolista, Madrid: Taurus 1973, p. 138).

${ }^{26}$ La misma tendencia en la última frase de la reseña: «Juan Ramón Jiménez sigue el camino de si mismo, que es el bueno».
} 
es la carta (ya citada) a Jiménez acompañada de algunos poemas y en la que se expresa así:

No estoy del todo descontento de ellos porque me parecen tan disparatados como sinceros. Yo procuro calcar la línea de mi sentimiento y no me asusto de que salga en el papel una figureja extraña y deforme, porque eso soy yo. (Pyp III, 1464)

Fue esto, sin embargo, un contento que no duró. Algunas semanas más tarde le confesó al amigo ser presa de dudas y tanteos, diciendo:

No estoy muy satisfecho de las cosas que hago últimamente. Estoy en un período de evolución y todavía no he encontrado la forma de expresión de mi nueva poesía. Lo último que se domina es la forma. (PyP III, 1464)

No precisa aquí el poeta el carácter de su «nueva poesía», pero no creemos equivocarnos afirmando que pensaba en una lírica que en vez de reflejar «almas violentas, ásperas y destartaladas» - las hemos encontrado en la mayoría de las «Galerías» en Helios- expresaría «sensaciones dulces y melancólicas» ( $P y P$ III, 1465) y tendría que ser «muy íntima» para «conmover a todos», porque «lo más hondo es lo más universal» ${ }^{27}$ —una poesía más equilibrada, en una palabra, como la que inspira largamente las Soledades revisadas.

En conclusión creemos poder afirmar que a pesar del conocido homenaje —a nuestros ojos: mi-laudatorio, mi-apologético ${ }^{28}$ - que rindió el poeta al «partero» Unamuno en mayo de 1904, Machado encontró a través de dudas, vacilaciones y reflexiones el buen camino por iniciativa propia en el transcurso de la primera mitad del año. De todos modos su rendición a las ideas de Unamuno fue sólo parcial: al componer el volumen de las segundas Soledades, no renegó de su pasado, conservando tanto el lema de «Galerías», al que dió la importancia y el ahondamiento que se sabe, como la mayoría de las composiciones insertadas en Helios bajo este título, salvo las tres más marcadas por el «spleen» (hoy: P.s. XVII, XVIII y $\mathrm{XX}$ ), incompatibles en 1907 con «la forma de expresión de [su] nueva poesía» anhelosamente buscada y encontrada finalmente hacia la mitad de 1904.

${ }^{27}$ Nuevo credo que Machado formuló por primera vez en la reseña de Arias tristes (PyP III, 1470).

${ }^{28}$ Le adscribimos este matiz porque Machado puede haber sentido la necesidad de reafirmar su gratitud a Unamuno, después de las citadas declaraciones de independencia. 


\title{
RESUMEN
}

Las «galerías» de Antonio Machado: Origen y evolución de una metáfora central de su poesía, por Hans Mattauch.

El presente artículo pretende esclarecer la repentina aparición y el uso de la metáfora de «galerías» en la temprana poesía de A. Machado. El poeta al parecer la encontró en $\grave{A}$ rebours de J.-K. Huysmans quien con ella había caracterizado la esencia de la poesía baudelairiana, hecho que incitó a Machado al estudio de Las flores del mal y a publicar, sobre todo en Helios (1903-04), una serie de poesías tituladas «Galerías» y marcadas por elementos temáticos y estilisticos de Baudelaire. Después integró la metáfora más hondamente en su discurso lírico y la consagró eligiéndola como título de una sección de las segundas Soledades. De esta indagación resulta una nueva valoración de la evolución de sus ideas estéticas en 1904 y de su relación con Unamuno en la misma época.

Palabras clave: Antonio Machado, Soledades, influencia de Baudelaire, evolución poética.

\begin{abstract}
The object of the present article is to explain the sudden appearance of the metaphor «galerías» in the early poetry of A. Machado and the use he made of it. He apparently discovered it in J.-K. Huysmans' $\dot{A}$ rebours, for whom it had served to characterize the essence of Baudelaire's poetry. This will have inspired Machado's study of Les fleurs $d u$ $m a l$ as well as a series of poems entitled «galerías», showing thematic and stilistic affinities with Baudelaire's and were published mainly in Helios. Subsequently he integrated the metaphor into the text of several other lyrics and, more important still, chose it as the title of a section of the revised Soledades. This evidence of the poems in Helios makes it necessary to reconsider Machado's esthetics in 1903-04 and his relation to Unamuno at the same period.
\end{abstract}

Key words: Antonio Machado, Soledades, influence of Baudelaire, poetic evolution. 